\title{
EARLY INTEGRATION OF FIRE SAFETY OBJECTIVES BETWEEN ARCHITECTS IN ACADEMIA AND IN PRACTICE
}

\author{
RAHMA M. DOHEIM \\ Architectural Engineering Department, University of Business and Technology, Kingdom of Saudi Arabia
}

\begin{abstract}
The timing of integrating the objectives of building's systems in the architectural design is governed by the decisions architects make. The architectural decisions regarding fire safety measures are, in some cases, hindered by cost. Such constraint keeps fire safety options to a minimum of code compliance considered at a late stage of the architectural design. Integrating and incorporating fire safety objectives at an early stage in the architectural design represents a quandary challenge for architects. This research focuses on assessing the perception of architects in academia and practice regarding their priorities for the early integration of natural smoke ventilation (NSV) in comparison to natural thermal ventilation (NTV) in buildings' design. The architectural design decisions influencing air and smoke flow patterns have been identified. The assessment was carried out through surveying architects in academia and in practice using the analytic hierarchy process (AHP) technique to measure their priorities of the early integration of either NSV or NTV objectives. The results show that there is an obvious perception gap between both architects in academia and in practice. The results also identify some of the reasons that contribute to the perception gap.
\end{abstract}

Keywords: early integration, architectural design, analytic hierarchy process (AHP), natural smoke ventilation, academia, fire safety.

\section{INTRODUCTION}

The fire safety system is not always considered seriously in the designs of buildings, for many reasons [1]-[3], including lack of understanding and cooperation between fire engineers and architects, the difficulty and complexity of using the fire codes by architects, and/or expensive costs of fire safety installation especially what is considered not vital because it is not "every day-use" and used only "in case of fire". Efforts to improve fire safety measures are in some cases hindered by cost. Such constraint keeps fire safety options to a minimum of code compliance considered at a late stage of the architectural design.

Knowing when to integrate the design strategies of any discipline in the architectural design is so critical that it could impact on the effectiveness of the whole building design. Moreover, it could help to avoid spending extra time and/or money that result from late integration or unnecessary early integration of the design strategies. Early integration of fire safety objectives, in most of the architectural designs, could be crucial to successful sustainable projects.

\section{LITERATURE REVIEW}

\subsection{Integration of fire safety objectives in the architectural design}

Architects' decisions are based on two basic sources: theoretical knowledge and practical experience [4]. For the last five decades, unsuccessful attempts and continuous efforts have been made to change the course of architecture education and to base it on a scientific foundation. More details on the problem of transferring the scientific knowledge to the architectural education are provided in [5]-[7]. The purpose of investigating the problem of 
transferring scientific knowledge is to decrease the gap between both academic and practice architects. A scientific basis would allow studying fire safety objectives and smoke ventilation process that would potentially allow architects to think safe and integrate those objective early in their designs.

This state of perplexity is attributed to several reasons including: (i) the personnel differences in perceiving knowledge and experience from design activities [8]; (ii) lack of common language between both sides regarding expressing their needs; and (iii) negativity in designers' attitude when it comes to scientific information [9]. Practice architects will have positive attitude towards information sources if it is perceived in architectural terms [7].

Integrating two or more systems means sharing some information between or among these systems, or maybe transferring data to be incorporated into one framework. From architectural aspect, Bachman [10] has classified integration into three categories based on the goal of each; physical, visual and performance integration. The physical integration is mainly about how building's elements, components or systems fit together in space. The visual integration is about combining building's components to produce a harmonized image. While the performance integration is about unifying, meshing or overlapping the functions of two components into one element. From an individual aspect, Boyer and Moore [11] indicated that there are at least three engineering disciplines involved in the design of integrated building system, which are: electrical, mechanical, and fire protection and must be coordinated together. This emphasizes the fact that this integration approach optimizes performance, and lead to time and cost efficiency.

No doubt that architects' knowledge is reflected in their design activities and the decisions they make. The decision of early or late integration could be driven by cost, size, nature, complexity of the project, and/or lack of awareness of the integration approach. Since 1980, the integration of fire safety objectives in the architectural design has been considerably investigated. Integrating fire safety objectives at early stage in the architectural design could increase the quality of the architectural and fire designs, and increases the effectiveness of buildings' systems operation [3]. The integration of fire safety system with other interacting systems (e.g. thermal ventilation) in the design is highly encouraged. According to the Chartered Institution of Building Services Engineers Application Manual 10 natural ventilation strategy must be integrated with smoke ventilation strategy since both follow the same path [12]. The British Standards 7346-5 advise the smoke ventilation designer to consider any potential interaction with other systems to avoid conflict in operation and to achieve the optimum success of the design [13]. Integration natural smoke ventilation (NSV) and natural thermal ventilation (NTV) was also emphasized in the Building Research Establishment report/BRE 375 indicating that strategies of NSV and natural building ventilation "in principle" can be combined effectively if designed with the integrated approach at an early stage of the design [14]. The major reason for most fire incidents is the communication problem between architects and fire engineers and that both are not standing on a common educational ground [15].

In building codes, it is essential to consider fire safety with ventilation at early stage of the design to benefit from "dual-purpose system" evaluation [16]. Building NTV is designed to achieve objectives that are different from the ones for NSV. However, the two systems can be incorporated compatibly at some stages of the design. This was emphasized in the CIBSE Application Manual AM10 [12] that natural ventilation strategy must be integrated with smoke ventilation strategy since both follow the same path. The British Standards 7346-5 [13] advise the smoke ventilation designer to consider any potential interaction with other systems to avoid conflict in operating and to achieve the optimum of the design. 
To fulfil client's expectations, CIBSE-B [16] encouraged integrating and linking between ventilation design, building envelope and structural design with costs and performance in mind. Integration was also emphasized in the BRE 375 report [14] indicating that strategies of NSV and natural building ventilation "in principle" can be combined effectively if designed with the integrated approach at early stage of the design.

\subsection{Smoke ventilation in retail buildings}

Not until the 1980s have the UK Building Regulations addressed smoke control performance design criteria in details for special occupancies as shopping malls and atria buildings. However, since the 1980s it is mandated by the British Building Regulations and Fire Codes to install smoke control system in typical buildings as part of the life safety systems' provision. Smoke ventilation has not appeared directly in the UK's regulations, except for some Local Acts as compensation for very tall building designs, or large compartment sizes in industrial/storage buildings. More recently, this has been formalized through a recommendation of Approved Document B Volume 1 [17], which recommends that new malls in England and Wales comply with British Standard BS 9999 [18]. This code recommends smoke ventilation for shopping malls and large shop units as an essential part of life safety provisions.

Since the late 1980s, the complexity level of the architectural designs has been elevated significantly. This elevated complexity in the designs required a broader set of regulations, which resulted in shifting the building and fire regulations from being prescriptive-based to performance-based. This shift allowed more freedom to architects, and more flexibility in judgments and decisions [19]. However, it burdens architects with a lot of work and responsibility to comply with building codes and regulations. With the elevated complexity in shopping malls and the increasing trend towards adopting large spatial areas and void spaces, architects face many challenges to meet building and fire codes. The criticality of shopping malls designs is that it usually contains large enclosed spaces with no physical separation, massive fire load, large number of people who are not familiar with the building; and occupants include disabled, children and elderly. In such buildings, it would be difficult to evacuate the building in a short time [20]. The large void areas in shopping malls are referred to as atria. Atrium is a major concern for architects and fire engineers as well. The vertical profile of an atrium space is critical because it is a large open space that in case of fire allows smoke spreading within all levels in the building quickly in a very short time.

Fire design scenarios differ according to the building typology [21]. The design criteria must, therefore, be defined clearly. For example, if the design criterion is life safety, the design objective would be to maintain specific height above occupants' heads free from smoke for an adequate period of time that allows occupants to evacuate safely. The main principle in a smoke control system design is to avoid being overpowered by the forces driving smoke [22]. However, the smoke control design considerations vary from building to another depending on many parameters including types of occupants, number of occupants, space functions, space profile, material used, fuel load, etc.

\subsection{Decision-making and the architectural design process}

There are four major factors that influence judgments and decisions that architects make during the design process [23]: (i) physical and economical (e.g. climatic conditions, nature of surroundings, market conditions, etc.); (ii) political (political restrictions); (iii) procedural (scheme development); and (iv) historical (e.g. history of the type of building, history of the 
architect's previous designs). The Royal Institute of British Architects (RIBA) outlined the design process in key work stages including appraisal, design brief, concept and outline proposal, and the design development, in which no clear description is given regarding the involvement of fire safety objectives in the design, but rather the description of the relationship between architects and clients [24]. However, if there is an emphasis on the early consideration of fire safety objectives in the design process, this would potentially improve the performance of NSV. For example, the shape of atria in any project is a decision that is made at early stage of the design, however; this decision would affect the smoke ventilation performance significantly [25]. Integrating fire safety objectives in the architectural design not only increase the quality of the architectural and fire designs, but also maximize the economic and the performance efficiency of the integrated systems if starts early in the design [2].

This paper focuses on the assessment of the current architects' priorities for early integration of design objectives of two closely connected systems: NSV and NTV. It provides an insight into the differences in architects' preferences for the stage of integration of NSV objectives and compares with those for NTV ones in retail buildings designs. Prior to the assessment of architect's priorities, the architectural design decision affecting air and smoke flow were identified. Those design decisions were driven by an excessive amount of empirical and numerical research work; more details are provided elsewhere [26].

\section{METHODOLGY}

This study is carried out via three stages; to identify and confirm the architectural design decisions influencing natural air and smoke flow movement, to assess architects' perception regarding the early integration priority of NSV and NTV in retail buildings design, and to verify architects' judgments and identify the knowledge gap in architects' perception. The first stage includes two steps: (i) identifying the architectural design decisions influencing air and smoke flow patterns from an extensive review of the literature and empirical studies, (ii) surveying experts in fire and building service engineering to confirm the identified design decisions and assure comprehensibility. The second stage includes surveying architects using analytic hierarchy process (AHP) technique to collect their judgments regarding the early integration priority they give for NSV and NTV objectives with respect to those identified design decisions. A pilot study was conducted prior to the AHP survey to test and refine the questionnaire. The third stage consists of interview surveys seeking further investigation to verify architects' judgments and test the conceptual hypothesis from the AHP survey.

\subsection{Identification and confirmation of the architectural design decisions: Experts' panel}

The architectural design decisions influencing the naturally-driven flow of air and smoke have been derived from an extensive review of the literature including experimental and numerical research, British regulations, and related governmental documents. There are twenty architectural design decisions that have been identified, which affect natural air and smoke flow, as shown in Table 1. In order to have an accurate and reliable assessment of architects' perception regarding the early integration priority of NSV and NTV objectives, it was necessary to refine and confirm those twenty design decisions. This was done by forming an experts' panel seeking the opinion of fire engineers and building service engineers experts along with a semi-structured interview. 
Table 1: List of the design decisions affecting air and smoke flow patterns: Experts' panel.

\begin{tabular}{|c|c|c|}
\hline $\begin{array}{l}\text { Design decision influencing air and smoke } \\
\text { flow }\end{array}$ & \multicolumn{2}{|c|}{ Modified action } \\
\hline 1. Interior and construction material (thermal) & \multicolumn{2}{|c|}{ OK. No action } \\
\hline 2. Opening orientation & \multicolumn{2}{|c|}{ OK. No action } \\
\hline 3. And double façade and glazing (thermal) & \\
\hline 4. Opening shape & \multicolumn{2}{|c|}{$\begin{array}{l}\text { OK. No action } \\
\text { Opening }\end{array}$} \\
\hline 5. Opening size & \multirow{4}{*}{ Combine } & Opening characteristics \\
\hline 6. Opening location (wall, ceiling) & & Opening characteristics \\
\hline 7. Opening height & & Opening characteristics \\
\hline 8. The direction of the opening & & Opening characteristics \\
\hline 9. Building size & \multirow{4}{*}{ Combine } & Building geometry \\
\hline 10. Building form & & Building geometry \\
\hline 11. Building envelop & & Building geometry \\
\hline 12. Roof shape & & Building geometry \\
\hline 13. Building location & \multirow{2}{*}{ Combine } & $\begin{array}{l}\text { Landscaping and adjacent } \\
\text { building }\end{array}$ \\
\hline 14. Landscaping and adjacent buildings & & $\begin{array}{l}\text { Landscaping and adjacent } \\
\text { building }\end{array}$ \\
\hline 15. Room size & \multirow{2}{*}{\multicolumn{2}{|c|}{$\begin{array}{ll}\text { Combine } & \begin{array}{l}\text { Space profile } \\
\text { Space profile }\end{array}\end{array}$}} \\
\hline 16. Room height & & \\
\hline 17. Spatial arrangements & \multicolumn{2}{|l|}{ Remove } \\
\hline 18. Interior and construction material (toxicity) & \multicolumn{2}{|l|}{ Remove } \\
\hline 19. Type of activity in the space & \multicolumn{2}{|l|}{ Remove } \\
\hline 20. Climatic conditions & \multicolumn{2}{|l|}{ Remove } \\
\hline
\end{tabular}

\subsection{Assessing architects' priorities for the early integration using the AHP survey}

After identifying and confirming the architectural design decisions influencing air and smoke movement [26], the early integration priorities for those decisions can be assessed. In order to gauge architects' perception for early integration priorities of NSV and NTV with respect to the selected design decisions, the AHP approach was used to design the questionnaire. With respect to the purpose of the survey, the selection criteria for the questionnaire used in this study were to allow responders to express their preference and provide their judgements, while assuring a high level of consistency.

The AHP is a multi-criteria decision making tool that allows assessing qualitative alternatives quantitatively with high level of consistency in judgment via assigning numerical weights. The high level of "consistency" in the judgments in the AHP reduces biased judgements through allowing consistency checking [27]. The AHP derives penetrating insights and reflects mental visions through assigning weights that are based on a logical and analytical understanding by participants [28]. The AHP helps to view the interaction among elements vertically and horizontally through all levels of the hierarchy. It allows all elements in the decision-making process to be viewed thoroughly in a series of interacting levels of the hierarchy, and help to test and identify conflict among components and subcomponents in different levels through decision-making process [27]. It incorporates the qualitative and quantitative aspects through defining and understanding the hierarchy problem and providing judgments via paired comparisons. This incorporation helps to select the most preferred alternative among different alternatives [29].

In order to structure a hierarchy, there are 4 steps to be followed. The first step is to define the problem, then set a hierarchy goal, decompose the problem (goal) into objectives in the level below the goal, and finally, develop the alternatives (to be prioritized) at the lowest 
level of the hierarchy. In this study, the hierarchy model consists of three levels starting with the goal (to prioritize the importance of early integration of NSV and NTV objectives) at the top of the hierarchy, which is decomposed to the objectives (the selected design decisions) in the middle, where it connects the alternatives (NSV objectives and NTV objectives) at the bottom of the hierarchy with the goal at the top. In any AHP model, the more criteria included in any given level, the less important each individual criterion may become, because the sum of the criteria's weights in the same level must equal 1 [30].

The pair-wise comparisons allow assigning relative weightings and priorities for each element on the same level with respect to the elements in the level above [29]. In order to maintain an acceptable level of consistency, the number of the elements in any level of the hierarchy should not exceed seven (plus or minus 2), and the lower than seven the greater the consistency level in judgments [28]. Every element in the hierarchy is being assessed using the pair-wise comparisons judgments with respect to each element in the level immediately above in the hierarchy. The pair-wise comparison judgments are based on assigning relative weights to the hierarchy elements using a scale from $1-9$, where 1 is the least important, and 9 is the most important. The assessments of the elements in any level of the hierarchy with respect to any element in the level above are expressed in a ratio forming a matrix, where each matrix represents a decision. Following the development of a comparison matrix, two values are calculated to check the consistency of the decision. The values are the "eigenvalue" and the "eigenvector". The decision is made by synthesizing and aggregating the consistent judgments representing the preference of the participants [30].

\subsection{Further interview}

The third stage of the methodology is to conduct further investigation through interviewing more architects. This further investigation aims to verify the AHP questionnaire results, test the interrelation between the architects' responses and develop conceptual theory.

\section{DATA COLLECTION}

\subsection{Confirmation of the architectural design decisions}

An experts' panel from both fields of fire safety and building service engineering was necessary to reflect different perceptions. A number of experts in both fields was contacted, and the selection criteria were to have "7+ years" of an extensive experience in NSV or NTV design in retail buildings, and/or other types of buildings. There were ten experts in fire safety engineering out of 69 and nine experts in building service engineering out of 70 who have met the selection criteria and accepted to form the experts' panel. They were invited to add, modify, and/or omit from the design decisions list based on the impact of each decision on the natural movement of air and smoke. The expert's panel advised modifications (combining or removing) were adopted as they contribute to the purpose of the questionnaire. It resulted in reducing the design decisions from 20 to seven (Table 1). However, no design decisions that could influence air and smoke movement were added. Those seven design decisions to be assessed by architects with regard to early integration of NSV and NTV are: (1) building geometry; (2) façade and glazing (in the context of thermal impact); (3) opening characteristics; (4) opening orientation; (5) landscaping and adjacent buildings; (6) space profile; and (7) construction and internal finishing material (in the context of thermal impact). 


\subsection{AHP survey}

After refining and confirming the design decisions and limiting them from 20 to seven decisions, the final hierarchy model were reset on which the questionnaires are based (Fig. 1). In this study, the aim of the AHP survey is to evaluate architects' priorities regarding the early integration of NSV and NTV objectives. The AHP survey is used for both prioritizing the criteria and alternatives, and measuring divergence in opinion. This is to be carried out by collecting judgements from relatively large sample of academic and practitioners. To fulfil this aim, judgments of experienced architects are collected and synthesized.

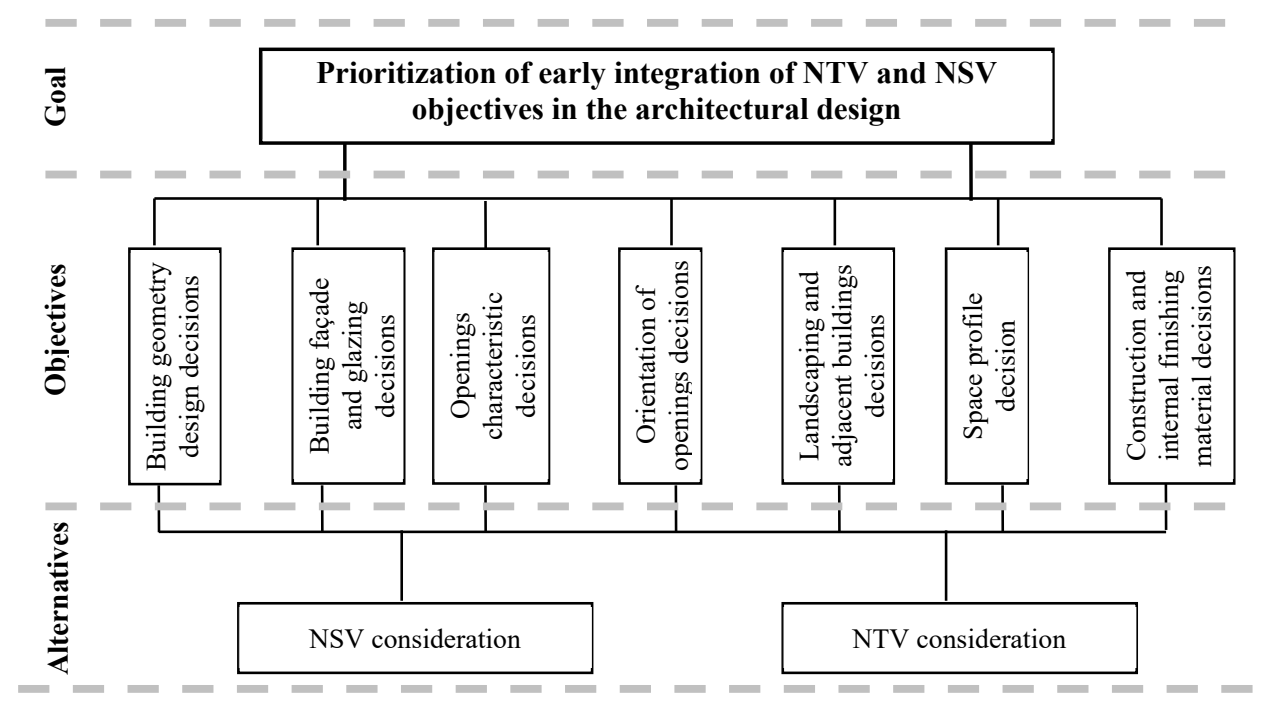

Figure 1: The hierarchy for prioritizing the early integration of NSV and NTV objectives.

In order to test the clarity of AHP questionnaire and validate the rationality and coherence of its questions before distribution, a draft copy of the questionnaire is piloted. Contacts were made with a sample of 12 architects from different universities and practices. This sample includes six academics who have been involved in research related to natural thermal and smoke ventilation and six practitioners who have been working on retail building projects. The questionnaires were designed to be accessed online, where participants were encouraged to provide comments and feedback on the delivery of the questionnaire. The outcomes of the pilot study were very valuable and helpful in refining and modifying the questionnaire.

Selecting the target respondents is a very critical step to avoid arbitrary opinions and misleading results. The selection criteria for respondents were as follows: academics must have experience of or interest in NTV and/or NSV systems, and practitioners must have work experience in designing large buildings with atrium space naturally-based or/and work experience in shopping or retail buildings design. Contact was made with 69 academic and practitioner architects from different cities and universities within the UK via both emails and phone calls to ensure that the questionnaire purpose is well perceived. This included 35 academic architects, and 34 practitioners. With continuous follow up, only 33 questionnaires were completed with consistent judgments, which represents $47.8 \%$ response rate. 
The AHP questionnaire was designed using the Expert Choice software. The Expert Choice is web-based software that allows constructing the hierarchy model through feeding the program with the hierarchy goal, objectives, and alternatives (input data). The evaluation process designed to be completed in two stages: (i) assessment of the objectives (in the 2nd level of the hierarchy) in relation to the goal (in the 1st level); and (ii) assessment of the alternatives (in the 3rd level) in relation to the objectives. Each stage consisted of a set of questions. The questionnaires were designed to be accessed online, and it consisted basically from 4 parts: the "welcome" screen; the questionnaire body: questions were designed on the basis of "pair-wise comparison"; the "results review" screen; and the "thank you" screen. The questions (paired comparisons) were viewed on different slides, one question for each slide. On each single slide and for each question there were two definitions provided for the terms used in the comparison, nine-degree scale, and a comment's space (Fig. 2).

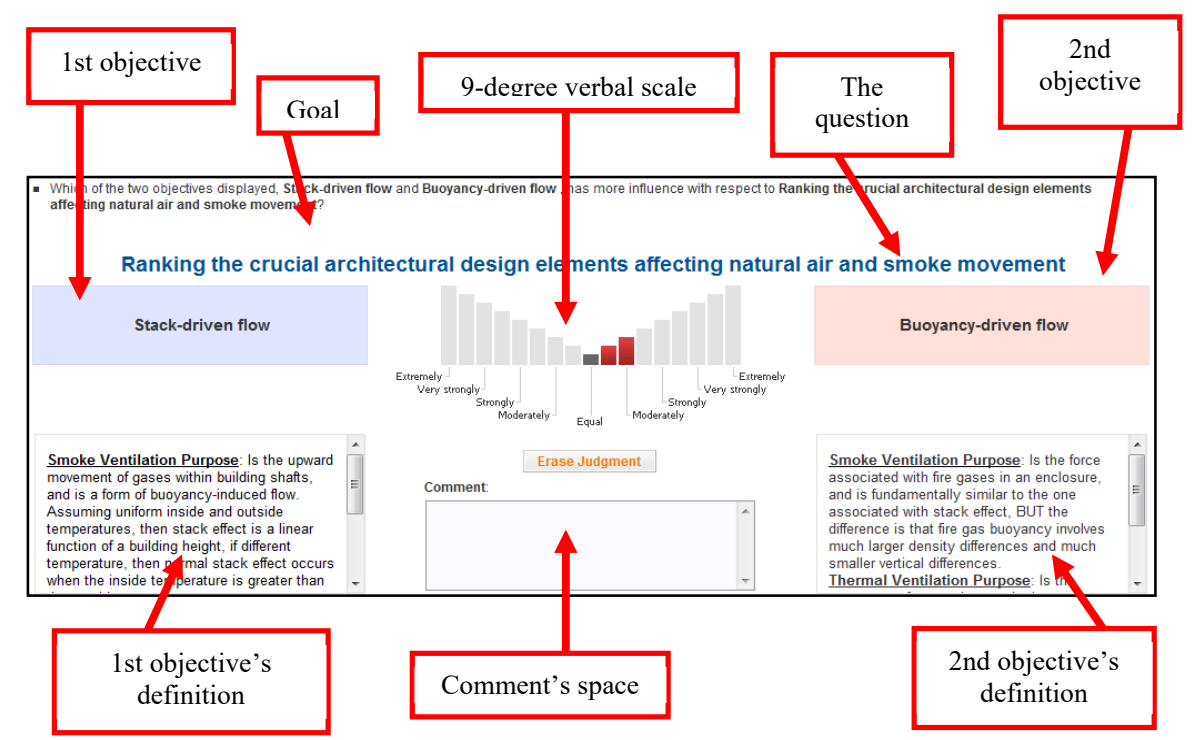

Figure 2: A screen of the question-slide showing its components.

The participants were asked to provide their judgments by expressing the relative importance of considering NSV and NTV early for each design decision. The weightings in the first stage represent the importance of each design decision with respect to the contribution of the early integration of NSV and/or NTV objectives. And, the weights of the second stage represent the importance of the early integration of NSV and NTV design objectives with respect to each design decision. The hierarchy decision would result from eight matrices. The first matrix size is $7 \times 7$, which consists of ratios of the relative importance of each objective (design decision) with respect to the goal (contribution of the early integration of NSV and/or NTV objectives). The other seven matrices size is $2 \times 2$, which consists of ratios of the relative importance of all the alternatives (early integration of NSV and NTV design objectives) in the third level with respect to each objective (design decision). 


\subsection{Further interviews}

Further investigation was carried out by looking thoroughly into the individual responses. Some responders were interviewed using open-ended questions to investigate the impact of the years of experience they have, complexity level of retail projects they have been involved in, and projects budget on the early design decision. Additional interviews were held with more architects to investigate the reasons for the priorities they provided.

\section{RESULTS AND DISCUSSION}

Using the Expert Choice program, architects judgments for the hierarchy model were pairwise compared and their matrices were calculated. Results are illustrated using the Performance Sensitivity Analysis, which is a graphical illustration that displays how the alternatives correspond with respect to each objective as well as overall. The relative importance of the objectives is displayed in percentages by the bars standing on the horizontal axis. The relative overall priority of the alternatives is presented in percentages by the bars on the vertical axis. The line segments intersecting with the objectives represent the relative importance of the alternatives with respect to each objective. The relative importance of the objectives and alternatives as perceived by academics is presented. It shows that in academics' perception the early integration of NTV objectives dominates all their design decisions, and that NTV priority is significantly higher than NSV. It also shows that although the "façade and glazing" decision is perceived by academics as the least importance regarding the early integration of NSV and NTV, it has the highest priority for early integration of NTV objectives amongst the design decisions. In addition, the figure manifests that the difference between NTV and NSV priorities is considerably large (Fig. 3).

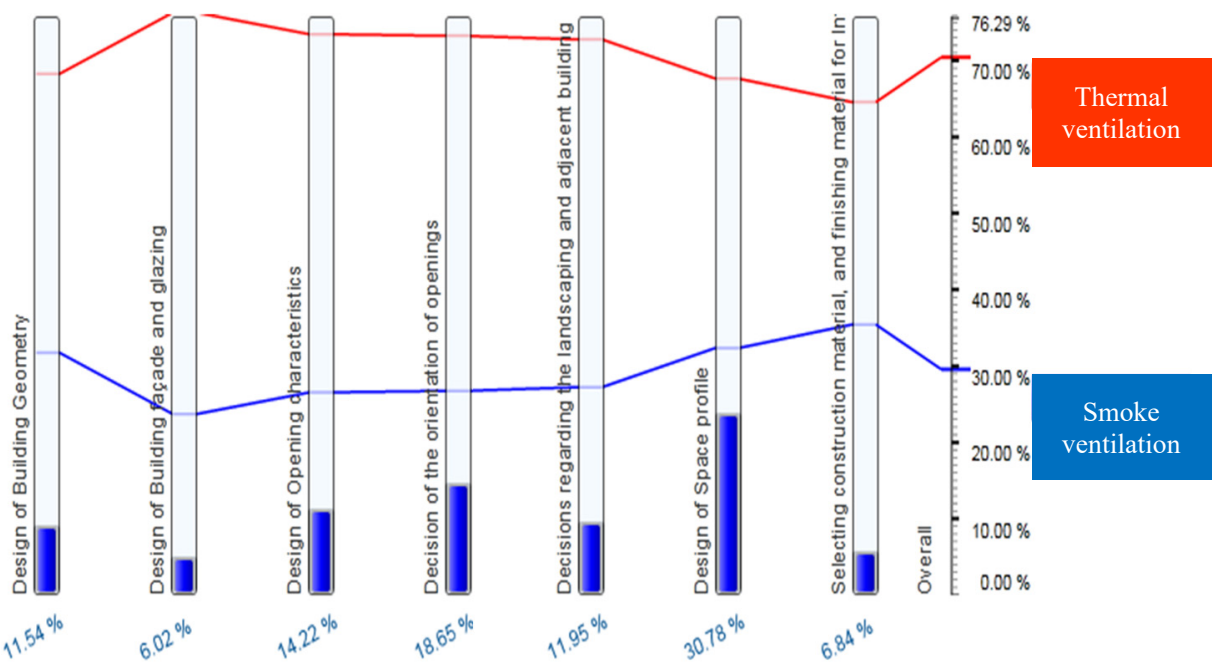

Figure 3: Performance sensitivity analyses of the academics' judgements.

On the other hand, the relative importance of the objectives and alternatives as perceived by practitioners shows that NSV is given more priority for early integration than NTV in the majority of their decisions. It can be noticed that the difference between NSV and NTV priorities is significantly large in some decisions (e.g. opening characteristics, atrium profile, 
geometry) when NSV is considered more important, and considerably small in other decisions (e.g. material of interior and construction, landscaping and adjacent buildings, orientation). This small difference indicates that practitioners perceive the early integration of NTV and NSV objectives with equal importance. The figure shows that the three most crucial decisions (geometry, space profile, and opening characteristics) are dominated by NSV objectives (Fig. 4).

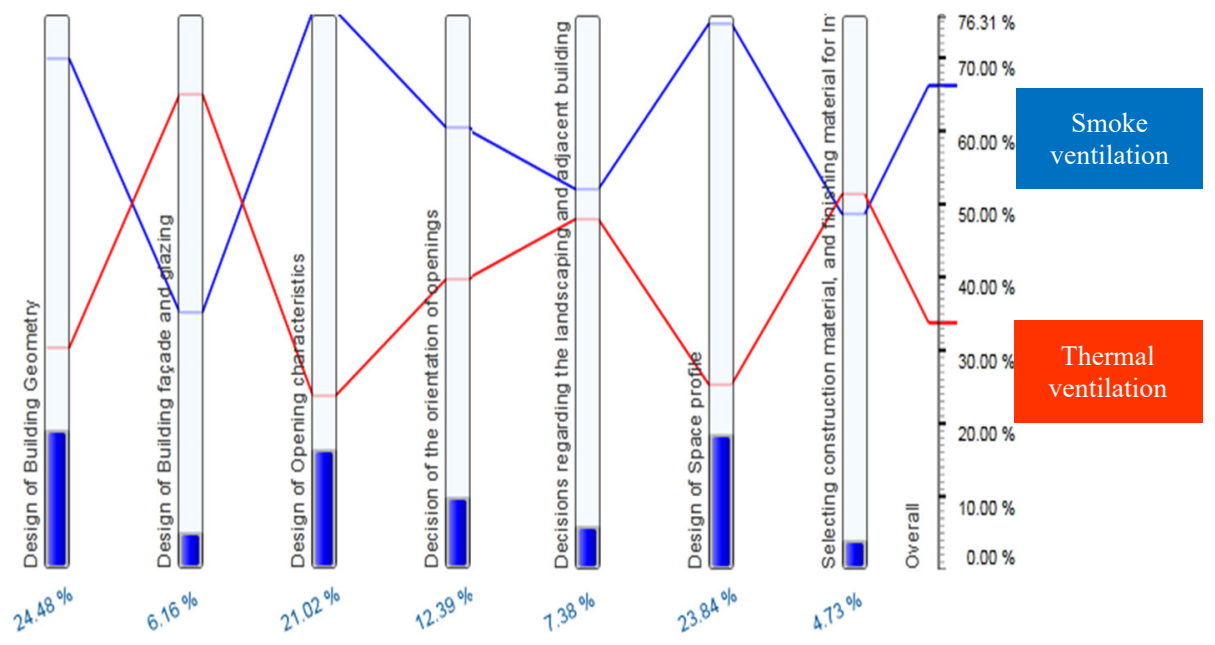

Figure 4: Performance sensitivity analysis to for practitioners' aggregated judgements.

Interestingly, when looking at the practitioners' judgments, their perception is not only different from the academics' but also contradicts it. Practitioners give more priority to the early integration of NSV objectives than NTV objectives in most of their design decisions in retail buildings.

The above findings manifest two important facts that academic and practice architects have different perceptions regarding the early integration of NSV/NTV objective, and that practice architects, oppositely from academic architects, consider early integration for NSV objectives more important than for NTV.

The results from the additional interviews with more practicing architects showed the following:

- Budget limitation: architects agreed on the fact that when the retail project is large, it is a prudent decision to involve fire engineer in the very early stages. Architects emphasized that clients not only would not compromise fire safety issues, but also would make it their ultra-priority. However, it is different if the project is small, in which architects can deal with straightforward fire safety issues.

- Complexity and experience: architects agreed that complexity of the building imposes the need for early involvement of fire engineer. However, sometimes the project could be simple but have one complex issue that needs fire engineered input, and only architects with experience know when to seek advice from a fire consultant. Architects see that an early integration decision is a matter of experience. It was agreed that only an experienced architect would be fully aware of the cost benefits of the early 
involvements of fire engineer and the early integration of fire safety objectives, more specifically, smoke ventilation.

- Knowledge and education: Architects responded that the building ventilation knowledge they have was basically perceived from undergraduate studies, including physical knowledge. Moreover, the fire safety knowledge they have perceived in the undergraduate studies was limited to escape routes and maximum travel distance, and some references to the regulation, but no physical knowledge regarding fire safety.

\section{CONCLUSIONS}

This paper provides an insight into the differences in design priorities for early integration of natural building and smoke ventilation among architects in academia and practice. Assessing the differences in design priorities allowed identifying the gap of fire safety knowledge in the architectural education. Architects in academia and architects in practice have contradictory perceptions for the early integration of NSV and NTV objectives in the design process. Academics appear to give more priority to the "every day-use" ventilation (NTV) and ignore the "in case of fire" ventilation (NSV) in the design decisions. Whereas, architects in practice contradicts with academics as they give more priority to NSV objectives in most of their design decisions, and NTV objectives are perceived to be less important for early integration.

It is concluded that practitioners gained some knowledge from the work experience that allowed them to be aware of the importance of early integration of NSV objectives, and academics lack this practical experience. The implication of the significant perception gap between academics and practitioners is that academics would continue to graduate architecture students with low emphasis on the early integration of NSV objectives in their views of design. Therefore, the knowledge gap in the architectural education and training regarding the fire safety and smoke ventilation should be filled through improving the architectural curriculum and emphasize the importance of the early integration of NSV objectives in designs.

\section{REFERENCES}

[1] Quintiere, J.G., Fire behaviour in building compartments. Proceedings of the Combustion Institute. 29(1), pp. 181-193, 2002.

[2] Peters, D.C., HVAC systems for the fire protection engineer. Fire Safety Journal, 7(1), pp. 65-80, 1984.

[3] Stollard, P., The integration of the objectives of fire safety into the process of architectural design. Fire and Materials, 14(3), pp. 117-122, 1989.

[4] Rambow, R. \& Bromme, R., Implicit psychological concepts in architects' knowledge: How large is a large room? Learning and Instruction, 5(4), pp. 337-355, 1995.

[5] Mackinder, M. \& Marvin, H., Design Decision Making in Architectural Practice, Building Research Establishment: Garston, Watford, 1982.

[6] Dorst, K., Design research: A revolution-waiting-to-happen. Design Studies, 29(1), pp. 4-11, 2008.

[7] Powell, J.A., Is architectural design a trivial pursuit? Design Studies, 8(4), pp. 187206, 1987.

[8] Carvalho, L., Dong, A. \& Maton, K., Legitimating design: A sociology of knowledge account of the field. Design Studies, 30(5), pp. 483-502, 2009.

[9] Sancar, F.H., Behavioural knowledge integration in the design studio: An experimental evaluation of three strategies. Design Studies, 17(2), pp. 131-163, 1996. 
[10] Bachman, L.R., Integrated Buildings: The Systems Basis of Architecture, Vol. 9, John Wiley \& Sons, 2004.

[11] Boyer, J.R. \& Moore, W.D., Integrated building systems: The hope has been that new technology and management tools will make building system integration much more seamless. Are we there yet? NFPA Journal, 102(6), p. 62, 2008.

[12] CIBSE Technical Publications Committee, Natural Ventilation in Non-Domestic Buildings, CIBSE Applications Manual AM10, CIBSE Publications, 2005.

[13] Standard BSI components for smoke and heat control systems: Functional Recommendations and Calculation Methods for Smoke and Heat Exhaust Ventilation Systems, Employing Time-Dependent Design Fire (BS7346-5), British Standard Institute, 2005.

[14] Williams, C., Perera, E., Morgan, H., Harrison, R., Caplen, B. \& Ferguson, A., Natural Ventilation in Atria for Environment and Smoke Control: An Introductory Guide, Building Research Establishment, 1999.

[15] Allen, W., Fire and the architect: The communication problem. Fire Safety Journal, 14(4), pp. 205-219, 1989.

[16] CIBSE-Guide B: Heating, Ventilating, Air Conditioning and Refrigeration, CIBSE: London, 2005.

[17] Department for Communities and Local Government (DCLG), Fire Safety Approved Document B, Volume 1: Dwelling Houses, 2006 edition incorporating 2010 amendments.

[18] BS B, 9999 Code of practice for fire safety in the design, management and use of buildings, BSI Global, 2008.

[19] Rasbash, D., Ramachandran, G., Kandola, B., Watts, J. \& Law, M., Evaluation of Fire Safety, John Wiley \& Sons, 2004.

[20] Morgan, H.P. \& Gardner, J.P., Design Principles for Smoke Ventilation in Enclosed Shopping Centres, Building Research Establishment: Garston, UK, 1990.

[21] Klote, J.H. \& Milke, J.A., Design of Smoke Management Systems, American Society of Heating, Refrigerating and Air-Conditioning Engineers: Atlanta, 1992.

[22] Klote, J.H., Smoke control. SFPE Handbook of Fire Protection Engineering, 3rd ed., National Fire Protection Association, pp. 274-291, 2002.

[23] Collins, P., Architectural Judgment, Faber \& Faber, 1971.

[24] Phillips, R., RIBA Plan of Work: Multi-Disciplinary Services, RIBA Publications Limited, 2008.

[25] Doheim, R.M., Yohanis, Y.G., Nadjai, A. \& Elkadi, H., The impact of atrium shape on natural smoke ventilation. Fire Safety Journal, 63, pp. 9-16, 2014.

[26] Doheim, R.M., Yohanis, Y.G., Nadjai, A. \& Elkadi, H., Bridging the knowledge gap between fire engineers and building service engineers: Using the analytic hierarchy process approach. Procedia Engineering, 145, pp. 1144-1152, 2016.

[27] Norris, G.A. \& Marshall, H.E., Multi-attribute Decision Analysis Method for Evaluating Buildings and Building Systems, Building and Fire Research Laboratory, National Institute of Standards and Technology, 1995.

[28] Saaty, T.L., The Analytic Process: Planning, Priority Setting, Resources Allocation, McGraw: New York, 1980.

[29] Saaty, T.L., How to make a decision: The analytic hierarchy process. European Journal of Operational Research, 48(1), pp. 9-26, 1990.

[30] Saaty, T.L. \& Vargas, L.G., Models, Methods, Concepts and Applications of the Analytic Hierarchy Process, Springer Science \& Business Media, 2012. 